\title{
Characterization and Histologic Localization of Human Growth Hormone-variant Gene Expression in the Placenta
}

\author{
Stephen A. Liebhaber, ${ }^{* \neq \$}$ Margrit Urbanek, Jhama Ray, ${ }^{\star 5}$ Rocky S. Tuan," and Nancy E. Cooke* \\ Departments of Medicine* and Human Genetics ${ }^{\ddagger}$ and the Howard Hughes Medical Institute, ${ }^{\S}$ University of Pennsylvania, Philadelphia, \\ Pennsylvania 19104; and Department of Orthopaedic Surgery," Thomas Jefferson University, Philadelphia, Pennsylvania 19107
}

\begin{abstract}
The human growth hormone-variant (hGH-V) gene is one of five highly similar growth hormone-related genes clustered on the short arm of chromosome 17. Although the pattern of expression of the adjacent normal growth hormone (hGH-N) and chorionic somatomammotropin (hCS) genes in this cluster are well characterized, the expression of the hGH-V gene remains to be defined. In previous studies, we have demonstrated that the hGH-V gene is transcribed in the term placenta and expressed as two alternatively spliced mRNAs: one is predicted to encode a 22-kD hormone (hGH-V), the other retains intron 4 in its sequence resulting in the predicted synthesis of a novel 26-kD hGH-V-related protein (hGH-V2). In the present report, we document the expression of both of these hGH-V mRNA species in the villi of the term placenta, demonstrate an increase in their concentrations during gestation, and directly sublocalize hGH-V gene expression to the syncytiotrophoblastic epithelium of the term placenta by in situ cDNAmRNA histohybridization. The demonstrated similarity in the developmental and tissue-specific expression of the hGH-V gene with that of the related hCS gene suggests that these two genes may share common regulatory elements.
\end{abstract}

\section{Introduction}

The human growth hormone-variant (hGH-V) ${ }^{1}$ gene (1) is a member of the superfamily of polypeptide hormone genes that includes five highly similar GH-related genes in a 45-kb cluster (2) located between q22 and q24 on chromosome 17 (3) and at least one more distantly related gene encoding prolactin ( $\mathrm{Prl})$ located on chromosome 6 (4). All five of the genes in the GH cluster are arranged in the same transcriptional orientation and are from $5^{\prime}$ to $3^{\prime}$ : normal human growth hormone (hGH$\mathrm{N}$ ), a chorionic somatomammotropin pseudogene (hCS-L), one of two nearly identical chorionic somatomammotropin

Address reprint requests to Dr. Liebhaber, Department of Human Genetics, University of Pennsylvania School of Medicine, Philadelphia, PA 19104.

Received for publication 28 October 1988 and in revised form 13 January 1989.

1. Abbreviations used in this paper: CM, host $\mathrm{C} 127$ cells, transfected gene under the metallothionein promoter; GH, growth hormone; hCS-L, human chorionic somatomammotropin pseudogene; hGH-N, normal human growth hormone; hGH-V, human growth hormone variant (gene); nt, nucleotide; Prl, prolactin.

J. Clin. Invest.

(c) The American Society for Clinical Investigation, Inc. 0021-9738/89/06/1985/07 \$2.00

Volume 83, June 1989, 1985-1991 genes (hCS-A), the hGH-V gene, and a second hCS gene (hCS-B) $(2,5)$. Each of these genes has in common a five-exon structure and each encodes a major secreted protein product of 22-24 kD. Two alternative splicing pathways have been identified in the hGH-related gene transcripts: use of an alternative splice-acceptor site within exon 3 of the hGH-N gene, resulting in the expression of a $20-\mathrm{kD}$ internal deletion form of $\mathrm{hGH}$ (6-8), and the retention of intron 4 in hGH-V transcript resulting in an mRNA (hGH-V2 mRNA) with the potential to encode a novel 26-kD protein (9). The expression of the $\mathrm{hGH}-\mathrm{N}$ gene is limited to somatotroph cells in the anterior pituitary and the expression of the hCS gene to the syncytiotrophoblastic epithelium of the placenta (10). The hPrl gene has a wider distribution of expression in vivo including the lactotroph cells of the anterior pituitary, the decidual basalis of the placenta $(11,12)$, and decidualized endometrium of the nongravid uterus during days 22-28 of the menstrual cycle (13). The in vivo expression of the hGH-V gene has recently been directly demonstrated by the isolation and sequence analysis of hGH-V and hGH-V2 cDNAs from the placenta (8). A placental growth hormonelike molecule found in maternal sera at increasing concentrations during gestation most likely represents a circulating form of at least one of the hGH-V gene expression products (14). In the present report, we attempt to further define $\mathrm{hGH}-\mathrm{V}$ gene expression by assaying for the presence of the hGH-V and hGH-V2 mRNAs in specific anatomic regions of the term placenta, at various times during gestation, and by directly identifying the expressing cells by in situ histohybridization to the encoded transcripts.

\section{Methods}

mRNA isolation and analysis. Stably transfected mouse fibroblast (C127) cell lines expressing the hGH-N (CM-GH) and the hGH-V (CM-V) genes have been previously described (9). RNA was prepared from these cultured cells by the method of Strohman et al. (15). Fresh placental tissues were obtained immediately after delivery or termination of pregnancy under a protocol approved by the Committee on Studies Involving Human Subjects of the University of Pennsylvania. The ages of the placentae were estimated from the dates of the mothers' last menstrual period. These tissues were immediately dissected into amnion, chorion, villous and decidual layers, and the tissues were rapidly frozen in liquid nitrogen. In the case of the $9 \mathrm{wk}$ gestational tissues, villous polyps were teased away from the membranes and were selected by flotation in normal saline solution. Floating villous tissue was removed from the saline and quickly frozen. RNA was then isolated from each sample (16). Northern analysis was carried out by standard procedures: RNA samples were denatured in $6.6 \%$ formaldehyde at $60^{\circ} \mathrm{C}$ for $15 \mathrm{~min}$, electrophoresed through $1.5 \%$ agarose, $6.5 \%$ formaldehyde-submerged slab gels (17), and transferred to nitrocellulose filters (18). The filters were hybridized with ${ }^{32} \mathrm{P}$-labeled $\mathrm{hPrl}$ cDNA (19) or hCS cDNA (Cooke, N. E., and S. A. Liebhaber, unpublished findings) insert probes as described in the text. 


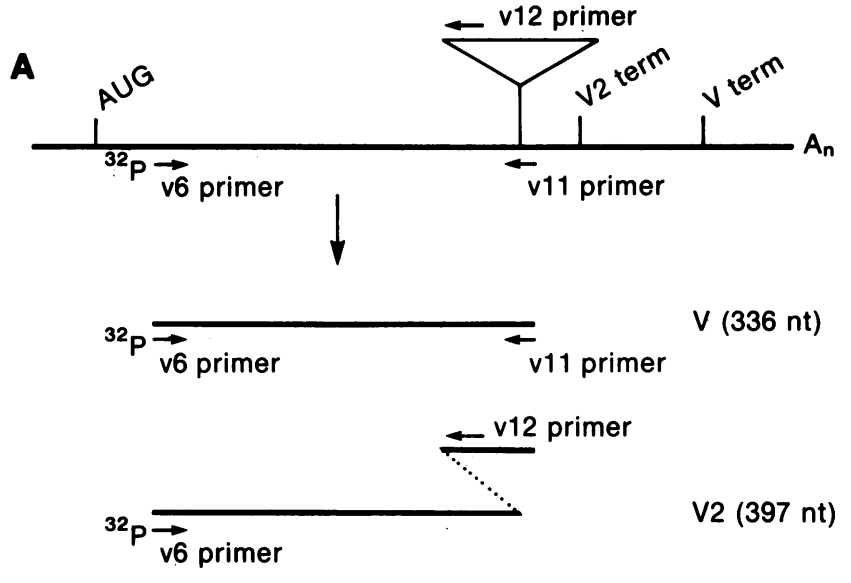

B

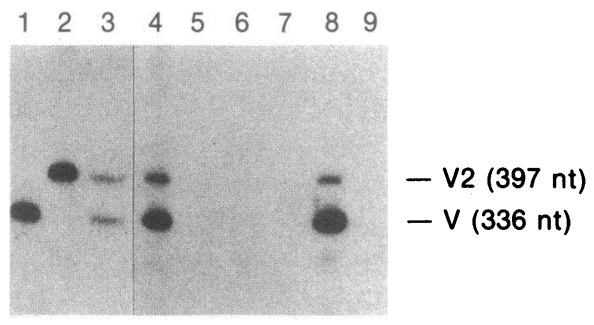

Figure 1. Detection of hGH-V and hGH-V2 cDNAs and mRNAs by the primer-dependent amplification reaction. $(A)$ The structures of hGH-V and hGH-V 2 mRNAs are diagrammed. The position of the 253-base intron 4, which is retained in hGH-V2 mRNA, is shown. The position and orientation of each of the three primers (v6, 111 , v12) used in the PDA reactions are indicated by the respective horizontal arrows. The 66 primer is labeled at its $5^{\prime}$ end with ${ }^{32} \mathrm{P}$ and the other two primers are unlabeled. The position of the translation initiation codon (AUG), hGH-V2 termination codon (V2 term), hGH-V termination codon (V term), and the poly A tail are shown. (B) PDA reaction using primers $v 6, v 11$, and $v 12$ carried out on singlestranded M13 preparations of hGH-V and hGH-V2 cDNA clones (lanes 1 and 2 respectively), and equal mixture of these two cDNAs (lane 3), reverse transcribed RNA from hGH-V and hGH-N transfected cell lines (lanes 4 and 5, respectively), and RNA isolated from the amnion, chorion, villous, and decidual layers of a normal term placenta (lanes $6,7,8$, and 9 , respectively). The reactions were resolved on a denaturing $5 \%$ acrylamide gel and directly autoradiographed. The position of the hGH-V and hGH-V2 specific amplified fragments are indicated along with their respective sizes.

cDNA synthesis and primer-dependent DNA amplification. To analyze mRNA by primer-dependent DNA amplification (20), cDNA was synthesized, purified, and then amplified by successive rounds of DNA synthesis primed by the antisense oligonucleotide used in the initial cDNA synthesis and by a more $5^{\prime}$ sense oligonucleotide labeled at its 5 -end with [ ${ }^{32}$ P]ATP (see Fig. $1 A$ ). The hGH-V, hGH-V2, and hCS oligonucleotides were each chosen for the uniqueness of their sequences compared to other members of the GH gene family. In addition, each was selected for its position within the gene so that each pair flanked at least one intron. In this way the amplified cDNA product could be specifically differentiated by size from amplification of any contaminating genomic DNA. The sequence and position of each of the oligonucleotides in a $5^{\prime}$ to $3^{\prime}$ orientation is as follows: primer v6 (GTCGCCTGTACCAGCTGGCATA), primer v11 (ATCTTCCAGCCTCCACATCA), primer v12 (TTTCTCTCCCCAGTCCCTGG), primer cs1 (GGTCGGCTCACAGGATGC), and primer cs2 (CATGACTCCCAGACCTCCT). The position of each of the hGH-V primers is shown in Fig. 1. The cs1 and cs 2 primers are located at bases 1540-1558 and 742-751, respectively, in the hCS gene (1). The level of sequence divergence between each of these primers and the corresponding region of the other expressed genes in the hGH gene cluster is as follows: v6 has a 5-base mismatch with hGH-N and a 7-base mismatch with hCS, v11 is a perfect match to hGH-N and hCS, v12 has a 8-base mismatch with hGH-N and a 6-base mismatch with hCS, csl has a 6-base mismatch with both hGH-N and hCS, and cs2 has a 4-base mismatch with both hGH-N and hGH-V. The oligonucleotides were prepared by the DNA synthesis service of the Cancer Center and Chemistry Departments of the University of Pennsylvania. For the reverse transcriptase reactions $5 \mu \mathrm{g}$ of total cellular RNA in $13 \mu \mathrm{l}$ of distilled water was added to an equal volume of $2 \mathrm{X}$ reverse transcriptase buffer $(100 \mathrm{mM} \mathrm{NaCl}, 20 \mathrm{mM}$ dithiothreitol, $100 \mathrm{mM}$ Tris- $\mathrm{HCl}$, pH 8.4, $10 \mathrm{mM} \mathrm{MgCl} 2,180 \mu \mathrm{g} / \mathrm{ml}$ actinomycin $\mathrm{D}$, and $400 \mu \mathrm{M}$ of each of the deoxynucleoside triphosphates) containing $0.15 \mu \mathrm{g}$ of the priming antisense $\left(3^{\prime}\right)$ oligonucleotide. The reactants were heated for $3 \mathrm{~min}$ at $92^{\circ} \mathrm{C}$ and then chilled to $4^{\circ} \mathrm{C}$ prior to the addition $20 \mathrm{U}$ of avian myeloblastosis virus reverse transcriptase (Life Sciences, Inc., St. Petersburg, FL). The reactions were mixed and incubated for $45 \mathrm{~min}$ at $50^{\circ} \mathrm{C}$. At completion of the incubation the cDNAs were purified by precipitation from $0.2 \mathrm{M}$ sodium acetate with $3 \mathrm{vol}$ of ethanol and dissolved in a buffer containing $10 \mathrm{mM}$ Tris and $1 \mathrm{mM} \mathrm{Na} \mathrm{F}_{2}$ EDTA, followed by phenol extraction and ethanol precipitation. The resultant pellet was desiccated and dissolved in $30 \mu$ of water. The amplification reactions were carried out in $16 \mathrm{mM}$ ammonium sulfate, $67 \mathrm{mM}$ Tris- $\mathrm{HCl}$, pH 9.0, $6.7 \mathrm{mM} \mathrm{MgCl}{ }_{2}, 6.7 \mu \mathrm{M} \mathrm{Na} \mathrm{N}_{2}$ EDTA, $10.7 \mathrm{mM} \beta$ mercaptoethanol, $1.4 \mathrm{mM}$ dimethylsulfoxide, $170 \mu \mathrm{g} / \mathrm{ml}$ bovine serum albumin, $33 \mu \mathrm{M}$ of each deoxynucleoside triphosphate, and $0.15 \mu \mathrm{g}$ of the antisense $\left(3^{\prime}\right)$ oligonucleotide primer and $0.15 \mu \mathrm{g}$ of the sense $\left(5^{\prime}\right)$ primer which was ${ }^{32} \mathrm{P}$-labeled at its $5^{\prime}$ terminus using polynucleotide kinase and $\left[\gamma_{-}{ }^{32} \mathrm{P}\right] \mathrm{ATP}$. The reactions were heated at $92^{\circ} \mathrm{C}$ for $4 \mathrm{~min}$, cooled to $54^{\circ} \mathrm{C}$ for $4 \mathrm{~min}$ with the subsequent addition of $2.5 \mathrm{U}$ of thermostable Taq polymerase (Perkin-Elmer-Cetus, Norwalk, CT). The reactions were then overlayed with mineral oil and incubated for 4 min at $72^{\circ} \mathrm{C}$. These samples were cycled 25 times through the following three temperatures: $90^{\circ} \mathrm{C}$ for $1 \mathrm{~min}$ (denaturation), $54^{\circ} \mathrm{C}$ for $30 \mathrm{~s}$ (annealing), $72^{\circ} \mathrm{C}$ for $4 \mathrm{~min}$ (synthesis). After completion of the cycles, the samples were placed on ice, and 4- $\mu$ l aliquots were removed, denatured in $80 \%$ formamide, electrophoresed through $5 \%$ polyacrylamide- $8 \mathrm{M}$ urea slab gels, and then directly autoradiographed. The relative intensity of each band was quantified by soft-laser densitometry (model SL-540-XL; Biomed Instruments, Inc., Fullerton, CA) of the autoradiograph. Exposure times were adjusted to be within the linear range of detection.

In situ cDNA-mRNA histohybridization. This was carried out using a recently published procedure (21). Fragments of human term placentas, consisting mostly of chorionic villi, were fixed in modified Carnoy's fixative at $-20^{\circ} \mathrm{C}$, dehydrated through a graded series of ethanol solutions, embedded in Paraplast, serially sectioned at $8 \mu \mathrm{m}$. thickness, and mounted on glass slides. For morphologic examination, the sections were stained with hematoxylin-eosin and visualized by bright field optics. The sections to be used for hybridization were treated with proteinase $\mathrm{K}$, followed by RNA denaturation with formamide. The cDNA probes, in the form of plasmids (see below), were labeled with biotinylated dUTP (16-mer; Enzo Biochem, Inc., New York) by nick-translation, and the reaction was monitored using $\left[{ }^{3} \mathrm{H}\right]$ dATP as a tracer. Hybridization was done using 5-10 $\mu \mathrm{g} / \mathrm{ml}$ of biotinylated probe (see below) at $39^{\circ} \mathrm{C}$ for $24 \mathrm{~h}$. After posthybridization washes with buffer containing $30 \%$ formamide to remove the unhybridized probe, sites of hybridization were detected using streptavidin conjugated with alkaline phosphatase (Enzo), and visualized histochemically by incubation with the chromogenic substrates 5-bromo-4chloro-3-indolyl phosphate and nitroblue tetrazolium (Sigma Chemical Co., St. Louis, MO). The sections were examined using the BH-2 microscope (Olympus Corp. of America, New Hyde Park, NY) equipped with Nomarski differential interference contrast optics.

The recombinant plasmids used contained either the hPrl cDNA (19), the hCS cDNA (Cooke, N. E., and S. A. Liebhaber, unpublished results), or the subcloned intron 4 region of the hGH-V gene (9). 


\section{Results}

Detection of $h G H-V$ and $h G H-V 2 m R N A s$ in placental villi by primer-dependent amplification. A highly specific assay is needed to detect the hGH-V mRNA in the placenta because of its $95 \%$ sequence identity to the far more abundant hCS mRNA. Although specific oligonucleotide probes can be used to detect hGH-V mRNA on Northern blots (8) or dot blots (22), we were not able to achieve an acceptable signal-to-noise ratio using this approach on Northern blots of placental mRNA. To overcome these problems, a primer-dependent amplification approach was designed to detect and compare the relative abundance of hGH-V and hGH-V2 mRNAs. Three oligonucleotide primers were synthesized (Fig. $1 \mathrm{~A}$ ). Antisense primer v12 should hybridize only to intron 4 of the hGH-V gene and therefore be specific for hGH-V2 mRNA, whereas antisense primer v11 should bridge exon 4 and 5 sequences and therefore be specific for hGH-V mRNA and not detect hGH-V2 mRNA. To demonstrate the specificity of this approach, these oligonucleotides were used to amplify singlestranded M13 templates (9) encoding an hGH-V cDNA, a hGH-V2 cDNA, and an equal mix of these two cDNAs. When these M13 DNA templates encoding either hGH-V or hGH-V2 cDNAs were amplified, only the predicted $336 \mathrm{nu}-$ cleotide (nt) fragment resulted when the hGH-V template was used (Fig. $1 B$, lane 1 ), and only the predicted 397-nt fragment resulted when the hGH-V2 template was used (lane 2). To demonstrate that both species of cDNA (hGH-V and hGH-V2) are amplified with equal efficiency we mixed equal amounts of each of these two templates and amplified them in the same tube. This resulted in amplification of equal amounts of 336-nt hGH-V and 397-nt hGH-V2 cDNAs (lane 3). To further demonstrate the specificity of this assay when beginning with mRNA, we synthesized and amplified cDNAs from mRNA isolated from C127 cell lines expressing the hGH-N (CM-GH cell line) or hGH-V (CM-V cell line) genes (8). When cDNA from CM-V cells was used as template, both hGH-V and hGH-V2 mRNA specific fragments were detected in a ratio of 3:1 (lane 4). This ratio of the two splicing products of the hGH-V gene agrees with the ratio previously obtained by Northern analysis of mRNA from the same cell line (9). Using CM-GH cDNA as template no amplified fragments were detected (lane 5). This negative result provides further evidence that the oligonucleotides were specific for hGH-V and hGH-V2 mRNAs since the sequence divergence between hGH-N and hGH-V in the region covered by the primers is less than or equal to the divergence between hCS and hGH-V. This primer-dependent amplification analysis therefore appears to be accurate and specific in detecting the hGH-V and the hGH-V2 mRNAs.

The primer-dependent amplification assay was applied to mRNA isolated from the various placental tissues: amnion, chorion, villi and decidua. In each case equal amounts of starting mRNA were used and verified to be intact by gel analysis of rRNAs (see Fig. 3, bottom). The amplified fragments representing hGH-V and hGH-V2 mRNAs were detected specifically in RNA isolated from the villi (Fig. 1, lane 8). Densitometric analysis of the hGH-V and hGH-V2 mRNA-specific bands revealed that the hGH-V2 signal represented $10 \%$ of total hGH-V gene transcripts in this tissue.

Induction of placental hGH-V gene expression during gestation. Villous mRNA from placentas at 9,25 , and $40 \mathrm{wk}$ of

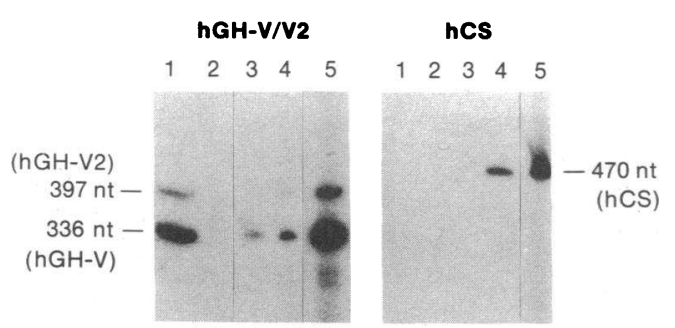

Figure 2. Induction of hGH-V and hCS gene expression in the developing placenta. The levels of hGH-V, hGH-V2 (left) and hCS mRNAs (right) were analyzed by the PDA reaction. The details of the hGH-V and hGH-V2 mRNA analysis were described in Fig. 1. The analysis of the hCS mRNA was carried out with a set of primers specific for this mRNA species (see Methods). In both cases the most $5^{\prime}$ primer was $5^{\prime}$ labeled with ${ }^{32} \mathrm{P}$ and the analytic gel of the reaction was directly autoradiographed. RNA from a cell line stably transfected with the hGH-V and hGH-N genes (lanes $I$ and 2, respectively) demonstrates the specificity of the reactions. Total placental RNA was analyzed from placental villi at 9,25 , and 40 wk of gestation (lanes 3, 4, and 5, respectively). The positions of the hGH-V, hGH-V2, and hCS mRNAs are each noted along with the size of the specific amplified fragment.

gestation were analyzed for hGH-V mRNA by cDNA synthesis followed by PDA as described above (Fig. 1). The results of these analyses are shown in Fig. 2 (left). Amplifications of cDNA synthesized from the CM-V and CM-GH cell lines (lanes 1 and 2, respectively) confirm the specificity of the assay. The analysis of the timed placental samples is shown in lanes 3-5. A faint hGH-V signal seen at 9 wk increases moderately at $25 \mathrm{wk}$ and very substantially by $40 \mathrm{wk}$. The hGH-V2 band which is clearly visible at $25 \mathrm{wk}$ and $40 \mathrm{wk}$ can also be visualized at 9 wk on prolonged exposures. The level of hGH-V2 mRNA detected by this assay as a percent of total hGH-V gene transcripts $(\mathrm{V}+\mathrm{V} 2)$ is $1.7 \%$ at $9 \mathrm{wk}, 3.1 \%$ at 25 wk, and $10 \%$ at $40 \mathrm{wk}$. In a parallel experiment, the same three mRNA samples were reverse transcribed and amplified using oligonucleotide primers specific for hCS mRNA (Fig. 2, right). As expected, the hCS-specific oligonucleotides did not detect hGH-V or hGH-N mRNA (lanes 1 and 2, respectively). Analysis of the timed placental samples (lanes 3-5) demonstrated a moderate signal at $25 \mathrm{wk}$ and a very dark signal at $40 \mathrm{wk}$. No signal was seen at $9 \mathrm{wk}$. Because of the variables of the procedure, direct comparison of beginning RNA levels cannot be inferred by comparing the intensities of the bands between the $\mathrm{hGH}-\mathrm{V}$ and $\mathrm{hCS}$ experiments.

Localization of $h G H-V$ gene expression to the syncytiotrophoblastic epithelium by in situ histohybridization. To determine the specific cell type(s) in the placenta expressing hGH-V, placental samples from a term gestation were fixed in a manner that preserved the mRNA, were then embedded in paraffin, and were sliced into 8- $\mu \mathrm{m}$ sections. hCS and hPrl cDNA probes to be used as positive and negative controls, respectively, were first nick-translated and hybridized to Northern blots containing total RNA from term placentae previously dissected into amnion, chorion, villi, and decidua. Fig. 3 demonstrates that the hCS probe hybridizes only to villi RNA $(10,23)$ and the $h P r l$ probe only to decidua $(24)$. These results are consistent with previous studies $(10,23,24)$. RNA samples isolated from a separate placental dissection contained Prl mRNA in the chorion mRNA as well as the decidua 


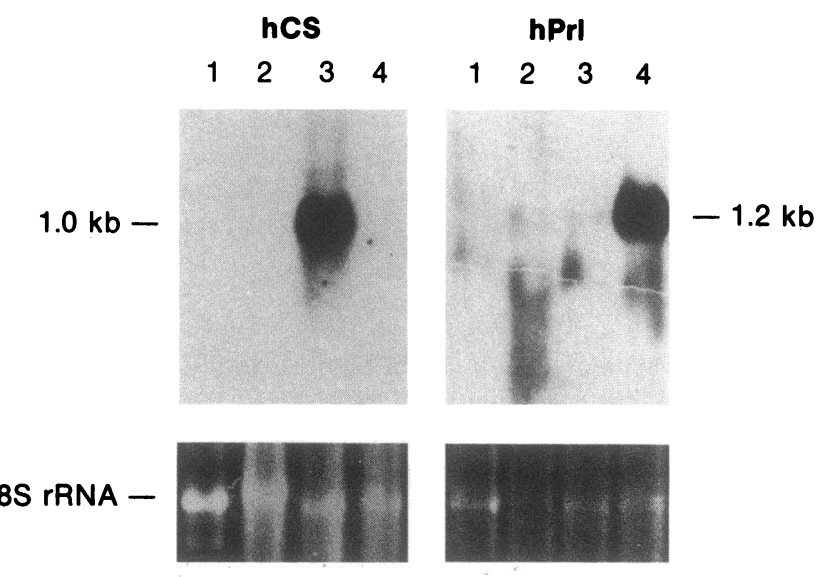

Figure 3. Sublocalization of hCS and hPrl mRNAs in the placenta by Northern analysis. Equal quantities of total RNA isolated from the amnion, chorion, villus, and decidual layers of the term placenta (lanes $1,2,3$, and 4, respectively) were resolved on a $1.2 \%$ agaroseformaldehyde gel, transferred to nitrocellulose paper, and hybridized with a ${ }^{32} \mathrm{P}$-labeled hCS or hPrl cDNA probe (left and right, respectively). An ethidium bromide stain of the 18S rRNA region of the gel is shown in the panel below the respective lanes of the autoradiograph.

(data not shown). We attribute this variability in the chorion mRNA to adherent decidua in some of the chorion membrane preparations. Such contamination is difficult to detect visually and completely remove from the chorion membrane and the mRNAs are analyzed as a combined chorion-decidual sample by some investigators (24). In no case did we detect any Prl mRNA in villous mRNA. An hPrl probe was therefore used as the negative control in the histohybridization studies of placental villi. Our previous Northern blots (9) as well as Fig. 1 have shown the hGH-V mRNA is anticipated to be expressed only by cells located in the villi. Since a full-length hGH-V or hGH-V2 cDNA probe would cross-hybridize to the related $\mathrm{hCS}$, a subclone of the intron 4 region included in the hGH-V2 mRNA was utilized to detect $\mathrm{hGH}-\mathrm{V}$ gene expression. A representative placental section stained with hematoxylin and eosin is shown in Fig. $4 \mathrm{~A}$. No decidual tissue was present. The three probes were labeled by nick-translation with biotinylated dUTP and hybridized to the sections. The hybridization sites were detected with streptavidin-alkaline phosphatase histochemistry and the slides were examined using Nomarski optics. The hCS probe hybridizes discretely to the syncytiotrophoblastic epithelium (Fig. $4 \mathrm{~B}$ ), while the hPrl probe fails to demonstrate specific hybridization to the tissue, consistent with the absence of decidual tissue in the sample (Fig. $4 C$ ). Interestingly, the intron 4 probe, specific for the hGH-V2 mRNA, hybridizes in a patchy manner to scattered regions of the syncytiotrophoblastic epithelium (Fig. $4 \mathrm{D}$ ). By comparing the kinetics of hybridization signal development between the hCS and the intron 4 probes, it was concluded that the patchy hybridization pattern of the latter genuinely reflected the cellular specificity of hGH-V2 expression. This conclusion is limited to the resolution of the histohybridization and expression of low levels of hGH-V2 by the remaining cells in the epithelial layer cannot be ruled out. Thus hGH-V2 is expressed at detectable levels by a small fraction of the cells making up the syncytiotrophoblastic epithelium, whereas hCS is expressed uniformly by all cells in this layer. In addition, examination of serial sections hybridized with the intron 4 probe (Fig. $4, E$ and
$F$ ) confirmed that the patchy signal was indeed cell-specific since the same cells stained throughout several serial sections.

\section{Discussion}

The existence of the hGH-V gene was first appreciated when extensive sequence analysis of the GH gene cluster demonstrated a gene that differed from the authentic GH gene by only 34 base substitutions and potentially encoded a protein product that differed from pituitary $\mathrm{GH}$ by 15 amino acids (1). Although no corresponding protein was known to be expressed, the fact that the sequence of the hGH-V gene appeared to possess all the structural attributes of an expressed gene, and that it could be expressed both transiently and stably in a number of transfected cell lines $(8,25)$ suggested that this gene may in fact function in vivo. The first suggestion that this gene was expressed in vivo came from the detection of signals on dot blots of placental mRNA and a single pituitary tumor mRNA using a hGH-V-specific oligonucleotide (22). It was estimated from that study that hGH-V expression in the placenta was $10^{4}$-fold lower than that of the hCS-A/hCS-B genes. This finding was confirmed and expanded upon by the isolation and sequence analysis of two major forms of hGH-V cDNA from a term placental library (9), one generated by the normal splicing of all 5 exons analogous to the hGH-N and the hCS mRNAs, and a second less prevalent form (hGH-V2) in which the fourth intron of the gene is retained in the mature mRNA. Based upon the representation of hGH-V gene transcripts in the term placental library we estimated that the hGH-V mRNAs constituted $\sim 0.05 \%$ of placental mRNA. Based upon the number of hGH-V and hGH-V2 clones which we had isolated and on the representation of the hGH-V and hGH-V2 mRNAs in a mouse cell line stably transformed with the hGH-V gene, we had estimated that hGH-V and hGH-V2 mRNAs are expressed at a 3:1 ratio. Although attempts to localize the hGH-V mRNA by Northern analysis using a specific oligonucleotide probe were unsuccessful due to background from the far more prevalent hCS mRNA, we were able to sublocalize hGH-V2 mRNA to the placental villi by using an hGH-V intron 4 probe. These studies therefore demonstrated the in vivo expression of two distinct forms of hGH-V mRNA and demonstrated that at least one (hGH-V2) was expressed specifically in the villous tissue (9).

To overcome the difficulties in specifically detecting hGH-V mRNA expression in the placenta we have used the polymerase chain reaction in the present study (20). Using this approach, we can detect and relatively quantitate the two hGH-V mRNAs in a single reaction tube. The experiments shown in Fig. 1 demonstrate the specificity and accuracy of this approach. By end-labeling one of the oligo primers with ${ }^{32} \mathrm{P}$ before the reaction, the amplified fragments become labeled and can be assayed directly by autoradiography thus eliminating the need for an additional step of hybridization to a labeled probe. This assay is highly specific in the presence of both high hCS or high hGH-N mRNA levels, and is useful even when the hGH-V mRNAs are present at very low concentrations. The amounts of amplified, specific DNA fragments in control experiments correlate quantitatively with the subnanogram amounts of control single-stranded cDNAs added to the assay. Background amplification of contaminating genomic DNA sequences can be specifically detected and 

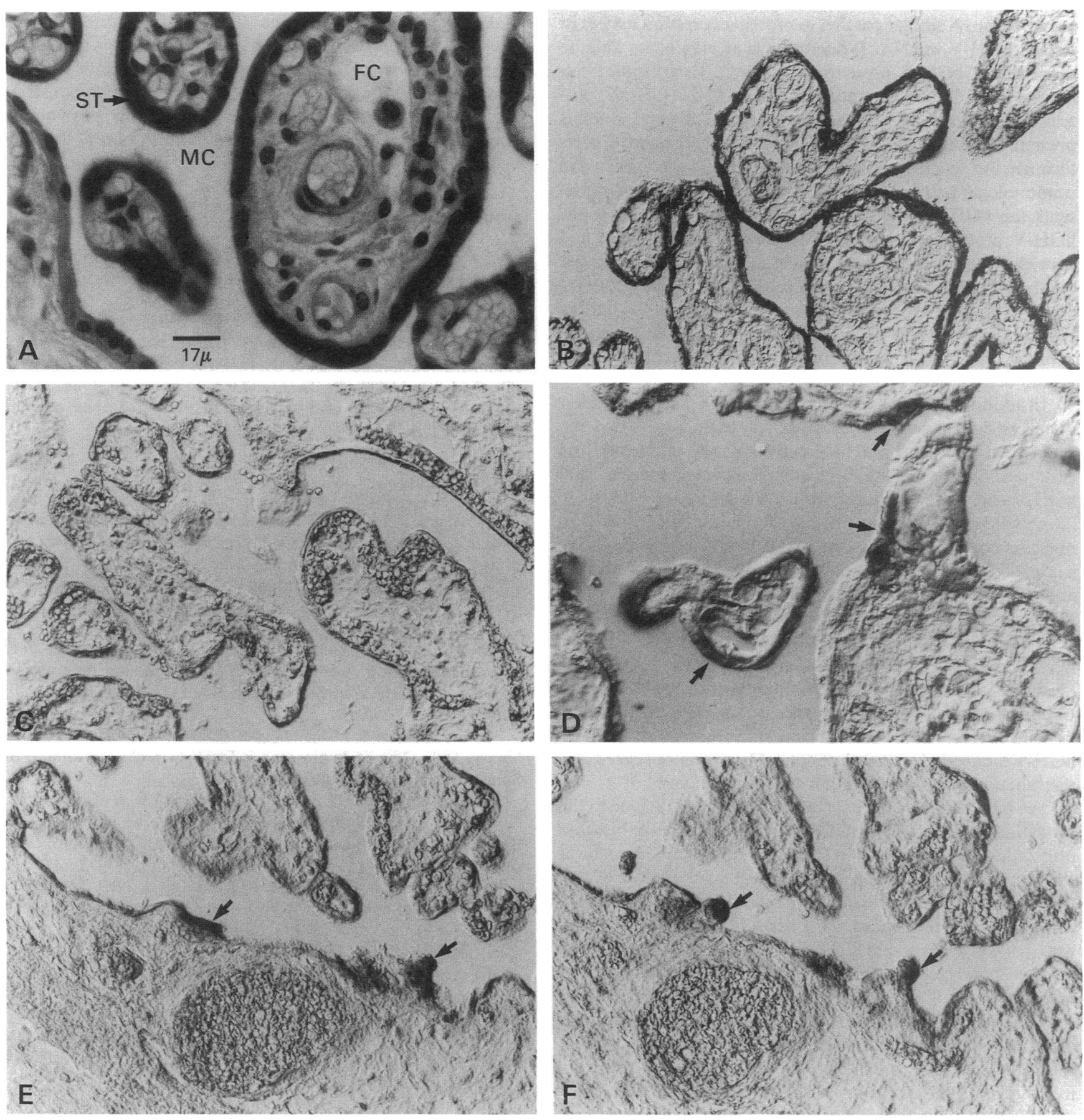

Figure 4. Cellular localization of mRNA transcripts of hCS, hPrl, and hGH-V2 in human term placenta by in situ cDNA-mRNA hybridization. (A) Histology of placental chorionic villi as shown by hematoxylin-eosin staining: $S T$, syncytiotrophoblasts; $M C$, maternal circulation (intervillous channels); $F C$, fetal circulation. $(B)$ In situ histohybridization with an hCS cDNA probe. (C) In situ histohybridization with a hPrl cDNA probe. $(D-F)$ In situ histohybridization with a probe containing intron 4 of hGH-V gene. Sections $E$ and $F$ are adjacent serial sections to illustrate the consistency of the hybridization signal localized to specific regions throughout the tissue. The bar in panel $A$ represents either $17 \mu \mathrm{m}(A, D)$ or $8.5 \mu \mathrm{m}(B, C, E, F)$.

separated from the measured product by using primers which flank introns (see Methods).

By using primer-dependent amplification of reverse transcribed cDNA, we can clearly detect hGH-V mRNA as well as hGH-V2 mRNA in the term placental villi. Because of the sensitivity and specificity of this approach, we can also detect these mRNAs at much lower levels in placental tissue from the first and second trimesters of pregnancy. The studies shown in Fig. 2 demonstrate a dramatic increase in hGH-V gene expression during gestation. Parallel analysis of hCS mRNA using the same primer-dependent amplification approach demonstrates a similar increase in concentration of mRNA. This increase in hCS mRNA with gestational age parallels the well-documented increase in hCS levels in maternal sera dur- 
ing gestation. A similar parallel in protein expression may exist for the hGH-V mRNA. While there is at present no definite proof that a hGH-V protein is expressed, Hennen and colleagues $(14,26)$ have detected a placental $22-\mathrm{kD}$ GH-like protein, unique from hGH-N by immunologic criteria, which is present in maternal plasma at increasing concentrations through the second and third trimesters. The physical and immunologic properties of this protein suggest that it represents the hGH-V gene product. We suspect that this is the $\mathrm{hGH}-\mathrm{V}$ protein and not hGH-V2 on the basis of size and because we have so far been unable to detect hGH-V2 in the media of transfected CM-V cells (unpublished data). The increase in levels of this protein during gestation and the finding that none is detectable in cord blood or amniotic fluid suggests strongly that hGH-V and perhaps hGH-V2 are human hormones of pregnancy.

In addition to the observation that $\mathrm{hGH}-\mathrm{V}$ gene expression increases during gestation, a more subtle finding is that the ratio of $\mathrm{hGH}-\mathrm{V}$ and $\mathrm{hGH}-\mathrm{V} 2 \mathrm{mRNAs}$ may change during gestation. The level of $\mathrm{hGH}-\mathrm{V} 2 \mathrm{mRNA}$ as a percentage of total hGH-V transcripts increases from $1.7 \%$ to $3.1 \%$ to $10 \%$ at 9 , 25 , and 40 wk of gestation, respectively. While this observation must be considered preliminary pending a more exhaustive study, additional data suggest that the relative rates of hGH-V and V2 mRNAs are subject to control. Although the level of hGH-V2 expression in term placenta is $\sim 10 \%$ of the hGH-V gene transcripts (present results), we have noted that when the hGH-V gene is expressed in stably transfected mouse fibroblasts the level of hGH-V2 mRNA increases to $30 \%$ of total (9, unpublished data). The significance of $\mathrm{hGH}-\mathrm{V} 2$ expression is difficult to assess at the present time since the expression of an hGH-V2-encoded protein has not yet been demonstrated and the function of such a protein is totally undefined.

We have localized the expression of the $\mathrm{hGH}-\mathrm{V}$ gene to the syncytiotrophoblastic epithelium by in situ cDNA histohybridization to sections of fixed and paraffin-embedded term chorionic villi. It was generally found that detection of this transcript required a maximal time period for color development of the alkaline phosphatase histochemical reaction. This was not surprising since the intron 4 probe is detecting hGH-V 2 mRNA which is present in $1 / 10$ the concentration of hGH-V, which is itself expressed at levels significantly lower than the related hCS mRNA. The patchy pattern of staining along the syncytiotrophoblastic epithelium suggested either that only selected regions express hGH-V2 or that only selected regions are expressing hGH-V2 abundantly enough for detection with this technique. This contrasts with the pattern seen with the hCS probe, for which only a short color development time was necessary to yield a uniform staining of the syncytiotrophoblasts.

The similarity in histologic localization and the parallel induction of mRNAs encoded by the hGH-V and the hCS genes suggests that these genes are controlled by common mechanisms. The close proximity of the hGH-V gene to the hCS genes in the growth hormone gene cluster may be directly relevant to their coexpression in placenta and parallel increase in transcriptional activity during gestation. These genes may share specific cis-acting regulatory elements or derive similar elements from local duplications within the cluster (5). The major difference between them is that the level of hCS mRNA is several orders of magnitude greater than hGH-V mRNA. In contrast to hGH-V and hCS, the expression of the linked
hGH-N gene is limited to the pituitary. Comparing the expression of the genes in this tightly linked cluster which share similar tissue specific expression but differ significantly in levels of expression (hGH-V vs. hCS) with those demonstrating a distinct tissue distribution and a distinct physiologic control (hGH-N) may be useful in the delineation of the relevant regulatory elements in the respective genes.

\section{Acknowledgments}

We gratefully acknowledge the aid of Mary Mulligan who carried out the in situ hybridizations and the cooperation of Drs. Deborah Driscoll and Michael Mennuti in obtaining the tissue samples.

This investigation was supported in part by National Institutes of Health grant P50 GM-32592 Sub 04 (Drs. Cooke and Liebhaber), National Foundation March of Dimes Basic Research Grants 1-1015 (Dr. Cooke) and 1-939 (Dr. Tuan) and U.S. Department of Agriculture grant 88-37200-3746 and National Institutes of Health grant HD-21355 (Dr. Tuan).

\section{References}

1. Seeburg, P. H. 1982. The human growth hormone gene family: nucleotide sequences show recent divergence and predict a new polypeptide hormone. DNA (NY). 1:239-249.

2. Barsh, G. S., P. H. Seeburg, and R. E. Gelinus. 1983. The human growth hormone gene family: structure and evolution of the chromosomal locus. Nucleic Acids Res. 11:3939-3958.

3. George, D. L., J. Phillips, U. Francke, and P. H. Seeburg. 1981. The genes for growth hormone and chorionic somatomammotropin are on the long arm of human chromosome 17 in region q21 to qter. Hum. Genet. 57:138-141.

4. Owerbach, D., W. J. Rutter, N. E. Cooke, J. A. Martial, and T. B. Shows. 1981. The prolactin gene is located on chromosome 6 in humans. Science (Wash. DC). 212:815-816.

5. Hirt, H., J. Kimelman, M. J. Birnbaum, E. Y. Chen, P. H. Seeburg, N. J. Eberhardt, and A. Barta. 1987. The human growth hormone gene locus: structure, evolution, and allelic variations. DNA (NY). 6:59-70.

6. Lewis, U. J., L. F. Bonewald, and L. J. Lewis. 1980. The 20,000 dalton variant of human growth hormone: location of the amino acid deletions. Biochem. Biophys. Res. Commun. 92:511-516.

7. DeNoto, F. M., D. D. Moore, and H. M. Goodman. 1981. Human growth hormone DNA sequence and mRNA structure: possible alternative splicing. Nucleic Acids Res. 9:3719-3730.

8. Cooke, N. E., J. Ray, M. A. Watson, P. A. Estes, B. A. Kuo, and S. A. Liebhaber. 1988. The human growth hormone gene and the highly homologous growth hormone variant gene display different splicing patterns. J. Clin. Invest. 82:270-275.

9. Cooke, N. E., J. Ray, J. G. Emery, and S. A. Liebhaber. 1988. Two distinct species of human growth hormone-variant mRNA in the human placenta predict the expression of novel growth hormone proteins. J. Biol. Chem. 263:9001-9006.

10. McWilliams, D., and I. Boime. 1980. Cytological Localization of placental lactogen mRNA in syncytiotrophoblast layer of the human placenta. Endocrinology. 107:761-765.

11. Golander, A., T. Hurley, J. Barrett, A. Hizi, and S. Handwerger. 1978. Prolactin synthesis by human chorion-decidual tissue: a possible source of prolactin in amniotic fluid. Science (Wash. DC). 202:311313.

12. Riddick, D. H., A. A. Luciano, W. F. Kusmik, and I. A. Maslar. 1978. De novo synthesis of prolactin by human decidua. Life Sci. 23:1913-1922.

13. Maslar, I. A., and D. H. Riddick. 1979. Prolactin production by human endometrium during the normal menstrual cycle. $\mathrm{Am}$. J. Obstet. Gynecol. 135:751-754.

14. Frankenne, F., J. Closset, F. Gomez, M. L. Scippo, J. Smal, and 
G. Hennen. 1988. The physiology of growth hormones (GHs) in pregnant women and partial characterization of the placental GH variant. J. Clin. Endocrinol. Metab. 66:1171-1180.

15. Strohman, R. C., P. S. Moss, J. Micon-Eastwood, D. Spector, A. Przbyla, and B. Patterson. 1977. Messenger RNA for myosin peptides: isolation from single myogenic cell cultures. Cell. 10:265-273.

16. Chirgwin, J. M., A. E. Przbyla, R. J. MacDonald, and W. F. Rutter. 1979. Isolation of biologically active ribonucleic acid from sources enriched in ribonuclease. Biochemistry. 18:5294-5299.

17. Lehrach, H., D. Diamond, J. M. Wozney, and H. Boedtker. 1977. RNA molecular weight determinations by gel electrophoresis under denaturing conditions, a critical reexamination. Biochemistry. 16:4743-4751.

18. Thomas, P. S. 1980. Hybridization of denatured RNA and small DNA fragments transferred to nitrocellulose. Proc. Natl. Acad. Sci. USA. 77:5201-5205.

19. Cooke, N. E., D. Coit, J. Shine, J. D. Baxter, and J. A. Martial. 1981. Human prolactin: cDNA structural analysis and evolutionary comparisons. J. Biol. Chem. 256:4007-4016.

20. Saiki, R. K., S. Scharf, F. Faloona, K. B. Mullis, G. T. Horn, H. A. Erlich, and N. Arnheim. 1985. Enzymatic amplification of betaglobin genomic sequences and restriction site analysis for diagnosis of sickle cell anemia. Science (Wash. DC). 230:1350-1354.
21. Tuan, R. S., B. T. Lamb, and C. B. Jesinkey. 1988. Mouse placental calcium-binding protein. II. Localization of mRNA in mouse and human placentae by in situ cDNA hybridization. Differentiation. 37:198-204.

22. Frankenne, F., F. Rentier-Delrue, M. L. Scippo, J. Martial, and G. Hennen. 1987. Expression of the growth hormone variant gene in human placenta. J. Clin. Endocrinol. \& Metab. 64:635-637.

23. Sciarra, J. J., S. L. Kaplan, and M. M. Grumbach. 1963. Localization of anti-human growth hormone serum within the human placenta: evidence for a human chorionic 'growth hormone-prolactin'. Nature (Lond.). 199:1005-1006.

24. Clements, J., P. Whitfeld, N. Cooke, D. Healy, B. Matheson, J. Shine, and J. Funder. 1983. Expression of the prolactin gene in human decidua-chorion. Endocrinology. 112:1133-1134.

25. Pavlakis, G. N., N. Hizuka, P. H. Gorden, P. H. Seeburg, and D. H. Hamer. 1981. Expression of two human growth hormone genes in monkey cells infected by simian virus 40 recombinants. Proc. Natl. Acad. Sci. USA. 78:7398-7402.

26. Hennen, G., F. Frankenne, J. Closset, F. Gomez, G. Pirens, and N. El Khayat. 1985. A human placental GH: increasing levels during second half of pregnancy with pituitary GH suppression as revealed by monoclonal antibody radioimmunoassays. Int. J. Fertil. 30:27-33. 